\title{
Review: all forms of nicotine replacement therapy are effective for smoking cessation
}

Silagy C, Lancaster T, Stead L, et al. Nicotine replacement therapy for smoking cessation. Cochrane Database Syst Rev 2004;(3):CD000146.

\section{What is the effectiveness of different preparations of nicotine replacement therapy (NRT) in achieving long term smoking cessation?}

\section{METHODS}

Data sources: Cochrane Tobacco Addiction Group Specialized
Trial Register, which is based on searches of the Cochrane
Central Register of Controlled Trials (Issue 4, 2003), Medline,
EMBASE/Excerpta Medica, PsycLIT/PsycINFO, and Science
Citation Index.
Study selection and assessment: randomised controlled trials
(RCTs) $\geqslant 6$ months in duration that compared NRT (including
gum, transdermal patch, intranasal spray, and inhaled and oral
preparations) with placebo or no treatment, or compared
different doses of NRT, and assessed smoking cessation.
Methodological quality of individual trials was assessed for
randomisation method, outcome assessment, and bias control.
Outcomes: smoking cessation (abstinence from smoking for
$\geqslant 6$ mo).

\section{MAIN RESULTS}

123 RCTs met the selection criteria; 103 compared NRT with placebo or no treatment, and 95 had $\geqslant 12$ months of follow up. All 5 preparations of NRT were better than placebo or no treatment in achieving smoking cessation at 6-12 months (table). In 7 RCTs that compared combinations of NRT with a single preparation, a modest increase in cessation was seen with the more intensive regimen (odds ratio [OR] $1.42,95 \%$ CI 1.14 to 1.76 ). In 4 RCTs that compared $4 \mathrm{mg}$ with $2 \mathrm{mg}$ of nicotine gum, the cessation rate was greater with $4 \mathrm{mg}$ in highly dependent smokers (OR 2.20, CI 1.50 to 3.25); no difference was seen in low dependence smokers. In 6 RCTs, a small benefit was seen with a nicotine patch at higher doses $(42 / 44 \mathrm{mg})$ than lower doses (21/22 mg) (OR 1.21, CI 1.03 to 1.42 ).

For correspondence: Mrs L Stead, Department of Primary Health Care Institute of Health Sciences, Oxford, UK. Lindsay.stead@dphpc.ox.ac.uk Sources of funding: NHS Research and Development National Cancer Programme, UK and NHS Anglia and Oxford Region Research and Development Programme, UK.

\section{CONCLUSION}

Any of 5 different preparations of nicotine replacement therapy are better than placebo or no treatment for achieving smoking cessation at 6-12 months.

\section{Commentary}

Tren he prevalence of smoking has remained stable over the past decade compared with dramatic declines in the 1980s. ${ }^{1}$ In fact, during the 1990 s, $60-70 \%$ of smokers reported not making an attempt to stop smoking in the previous year. ${ }^{2}$

Appropriate use of NRT helps smokers succeed in quitting and reduces smoking prevalence. The comprehensive review by Silagy et al extends meta-analyses reported by Fiore et $a l^{3}{ }^{3}$ with additional trials of nicotine gum, patch, and inhaler, as well as recent tablet studies. ORs are similar to those of the review by Fiore et al. Silagy et al acknowledge that a publication bias might exist. Including all unpublished negative trials would decrease the effects shown.

These findings have broad applicability to nurses in primary care, acute care, rehabilitation, obstetric, and paediatric settings. In particular, it is essential to convey a meaningful message to smokers that any of 5 forms of NRT improve success by 1.5 to $\geqslant 2$ times, 8 weeks of therapy is as effective as longer treatment, $4 \mathrm{mg}$ of nicotine gum is more effective than $2 \mathrm{mg}$ of gum for dependent smokers, and tapering NRT is no better than abrupt NRT withdrawal. As noted in Reducing tobacco use, the lack of progress in tobacco control is not related to a lack of knowledge about what to do, but more to a failure to implement proven strategies. ${ }^{4}$ NRT is a critical component in comprehensive tobacco control efforts. Karen Ahijerych, RN, PhD Ohio State University College of Nursing Columbus, Ohio, USA

1 Siegel M, Mowery PD, Pechacek TP, et al. Trends in adult cigarette smoking in California compared with the rest of the United States, 1978-1994. Am J Public Health 2000;90:372-9.

2 Wewers ME, Stillman FA, Hartman AM, et al. Distribution of daily smokers by stage of change: current Population Survey results. Prev Med 2003;36:710-20.

3 Fiore MC, Bailey WC, Cohen SJ, et al. Quick reference guide for clinicians. Treating tobacco use and dependence. Rockville, MD: US Department of Health and Human Services, 2000. http://www.surgeongeneral.gov/ tobacco/tobaqrg.htm

4 Centers for Disease Control and Prevention. Reducing tobacco use: a report of the Surgeon General. Atlanta: US Department of Health and Human Services, 2000. http://www.cdc.gov/tobacco/sgr/sgr_2000/index.htm

Nicotine replacement therapy (NRT) v placebo or no treatment (control) for smoking cessation at 6-12 months*

\begin{tabular}{|c|c|c|c|c|}
\hline Comparison & Number of trials ( $\mathrm{n}$ ) & Weighted event rates & RBI $(95 \% \mathrm{Cl})$ & NNT (Cl) \\
\hline Any NRT $v$ control & $103(38602)$ & $16 \% \vee 10 \%$ & $58 \%(50$ to 67$)$ & $17(15$ to 17$)$ \\
\hline Gum v control & 52 (17 819) & $18 \%$ v $12 \%$ & $48 \%$ (38 to 59$)$ & 17 (15 to 20$)$ \\
\hline Patch $v$ control & 37 (16 228) & $14 \% \vee 8.1 \%$ & $71 \%$ (55 to 88$)$ & 17 (15 to 20$)$ \\
\hline Intranasal spray $v$ control & 4 (887) & $24 \% \vee 12 \%$ & $102 \%$ (49 to 173 ) & $9(6$ to 15$)$ \\
\hline Inhaler $v$ control & $4(976)$ & $17 \%$ v $9.1 \%$ & $90 \%$ (36 to 167$)$ & $13(9$ to 25$)$ \\
\hline Tablet $v$ control & $4(2739)$ & $16 \% \vee 9 \%$ & $87 \%$ (52 to 223$)$ & $13(10$ to 20$)$ \\
\hline
\end{tabular}

*Abbreviations defined in glossary; weighted event rates, RBI, NNT, and Cl calculated from data in article using a fixed effects model. 